\title{
APLIKASI ANALIS JALUR UNTUK HUMAN RELATIONS, LINGKUNGAN KERJA TERHADAP MOTIVASI KERJA DAN KINERJA PEGAWAI KANTOR WILAYAH KEMENTERIAN AGAMA PROVINSI SUMATERA BARAT
}

\author{
Yulina Eliza ${ }^{1}$, Hendra Yuharmain ${ }^{2}$, Suheri $^{3}$ \\ Sekolah Tinggi Ilmu Ekonomi "KBP" Padang \\ J1. Khatib Sulaiman No.61 Lolong Belanti Padang Utara 25136 - Sumatera Barat \\ E-mail : yulinaeliza@akbpstie.ac.id
}

\begin{abstract}
This study aims to determine the effect of human relations and work environment on the performance of the employees of the Regional Office of the Ministry of Religion of West Sumatra Province through work motivation as an intervening variable. The study population was all employees of the Regional Office of the Ministry of Religion of West Sumatra Province with the status of Civil Servants. The research sample used proportionate stratified random sampling technique. Primary and secondary data used in the study amounted to 67 people. Data analysis using path analysis and hypothesis testing using the test with SPSS were used to analyze the data. The results showed that: Human relations has a significant effect on work motivation and employee performance. The work environment has a significant effect on work motivation, but not on employee performance. Work motivation has a significant effect on employee performance.
\end{abstract}

Keywords: Human Relations, Work Environment, Work Motivation, Employee Performance

\section{PENDAHULUAN}

Kementrian agama wilayah Sumatra Barat memiliki peran dan fungsi yang semuanya bersumber dari peraturan dan undang undang, dimana dari data yang didapatkan berdasarkan data pra survey yang dilaksanakan dibulan Desember 2019, data survey menunjukkan masih tergolong rendah.

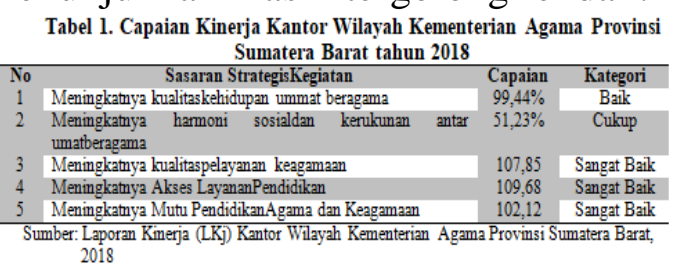

Berdasarkan data dapat kita ketahui gambaran dari strategis apa yang akan ditetapkan dari perjanjian kinerja pada tahun 2018, terdapat tiga program kerja yang berhasil dilaksanakan dengan sangat baik yakni meningkatnya pelayanan keagamaan $(107,85 \%)$, akses pelayanan kesehatan $(109,68 \%)$ dan terus bertambahnya nilai pendidikan agama dan keagamaan (102,12\%), sementara ada satu program kerja yang mendapatkan realisasi capaian kinerja baik yaitu meningkatnya kualitas kehidupan ummat beragama $(99,44 \%)$, dan satu program kerja yang realisasi capaian kinerja cukup yaitu meningkatnya harmoni social dan kerukunan antar umat beragama $(51,23 \%)$.

Penilain dari sebuah kinerja pegawai yang dilakukan Instansi pemerintah yakni kementrian agama, dimana hampir semua sasaran kerja dari pegawai (SKP) yang dituangkan dalam peraturan pemerintah No.46 tahun 2013 dimana prestasi kerja dapat diimplementasikan sebagai mana seharusnya di setiap awal tahun kinerja pegawai. Disinilah letak penting dibuatnya sasaran kerja dari pegawai agar tercapainya tujuan. Adapun yang menjadi unsur penting yang digunakan untuk mencapai sasaran kinerja antatart SKP dan PKP pada intasi pemerintah yakni kementrian agama di propinsi Sumatra Barat dengan cakupan formula $60 \%$ bobot SKP + 40\% PKP. Dalam menilai SKP aspek-aspek yang diukur yaitu kuantitas, 
kualitas, waktu dan biaya, sedangkan penilaian PKP oleh atasan terdiri dari aspek-aspek integritas, orientasi pelayanan, komitmen, kedisiplinan, dan kerjasama. Setelah aspek-aspek SKPdan PKP dinilai maka dihitung rata-rata bobot dan nilai dari kinerja masingmasing pegawai dapat dilihat pada Tabel 2 adalah bobot nilai kualifikasi kinerja.

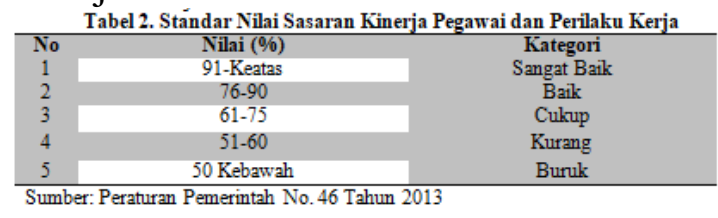

\section{TINJAUAN PUSTAKA}

Gambaran dari sebuah pencapaian yang diukur dengan sebuah kinerja dapat diketahui dan diinformasikan bahwa sebuah lembaga/instansi pemerintah bekerja dengan dasar adanya sebuah visi yang diamanahkan demi tercapai apa yang menjadi tujuan yang diinginkan serta dapat mengetahui dampak yang di timbulkan dari hasil kinerja yakni nilai tambah atau berkurangnya dari sebuah capaian tersebut. Sulaksono (2019: 91) menjelaskan bahwasanya sebuah kinerja yang dilakukan dengan terukur dan terencana serta sistematis akan tercapainya sebuah hasil dan nilai atas sebuah pekerjaan dan kinerja dari pergawai serta organisasi tersebut.

Terbangun sebuah komunikasi yang baik akan memberikan dampak positif terhadap keberlangsungan sebuah organisasi, apakah itu sebuah komunikasi yang dibangun dengan pola persuasive, dimana semuanya dilakukan untuk tercapainya apa yang menjadi tujuan dari sebuah organisasi tersebut (Adawiyah,2019:3). Semuanya tidak lepas dari peran seorang pimpinan/manajer dalam organisasi tersebut dimana mampu membangun pola komunikasi yang berakar dari bawahan ke pimpinan. Davis dalam Susanti, dkk (2014) mengemukakan bahwasannya pola interaksi yang dibangun dengan baik akan memberikan hasil yang baik, walau dalam situasi kerja dari organisasi tersebut, hal ini juga dikemukakan oleh musnef dalam Simanjuntak, dkk (2016) terbangunnya pola interakasi dengan lainnya, yang merupakan upaya menciptakan hubungan yang lebih baik, baik secara formal maupun tidak formal, tentunya tidak terlepas dari pola interaksi yang dibangun dari pimpinan kepada bawahan demi tercapainya apa yang menjadi tujuan dari organisasi yang sudah ditetapkan.

Terlaksannya sebuah aktifitas yang rutin disebuah organisasi tidak terlepas dari adanya lingkunga kerja dan karyawan yang beraktifitas sehari hari secara utuh dan keseluruhan dalam menyelesikan setiap kerja yang dilakukan (Widodo, 2015;95). Pendapatkan lain yakni Netisemito dalam Sangki (2014;541) mengungkapkan bahwasanya lingkungan kerja dapat memberikan pengaruh dalam setiap aktivitas kerja yang ada dalam perusahaan.

Kemampuan untuk dapat memberikan sebuah inpirasi, memotivasi dan kemampuan untuk dapat memberikan dorongan dengan penuh nilai keikhlasan dan diikuti kesungguhan akan dapat memberikan hasil kerja yang terukur, terarah dan berkualitas sebagaimana hal ini diungkapkan Afandi (2016:12). Sikap motivasi yang baik dan terrencana akan dapat memberikan pengaruh terhadap pegawai/karyawan. Hal ini juga di ungkapkan oleh Sutrisno (2013;109) bahwasannya motivasi akan menjadi pendorong dalam menyelesaikan setiap pekerjaan tersebut. Komponen lain yang di ungkapkan Wijono dalam Duha $(2014 ; 186)$ bahwasanya motivasi akan memunculkan arah dan perilaku untuk dapat melakukan interprestasi.

Penelitian ini dikembangkan dari kerangka konseptual sebagai mana pada gambar berikut : 


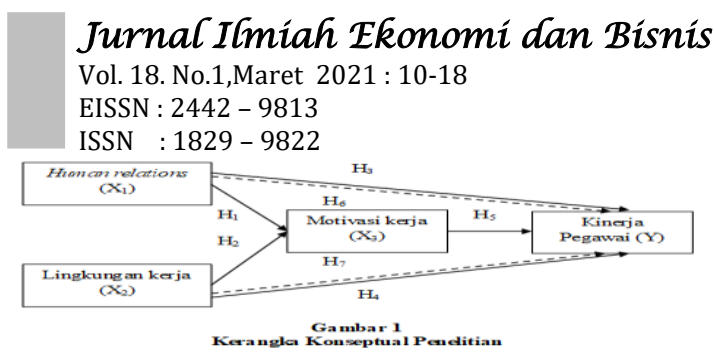

\section{METODE PENELITIAN}

Penelitian melibatkan responden sebanyak 67 responden pada pegawai kementrian agama Sumatra Barat. Penelitian ini dilakukan dengan teknik probability sampling dan proportionate stratified random sampling, metodenya dengan memberikan peluang yang sama pada setiap unsur yang menjadi populasi dalam penelitian ini (Sugiyono, 2013;120). Adapun teknik analisis yang digunakan dalam penelitian ini yakni analisis jalur dan uji hipotesis (SPSS)

\section{HASIL DAN PEMBAHASAN}

Pada penelitian ini analisis jalur dibagi menjadi dua substruktur, yakni: (1) Substruktur I menganalisis pengaruh human relations dan lingkungan kerja sebagai variable eksogen dan variable motivasi kerja sebagai variable endogen. (2) Substruktur II menganalisis pengaruh human relations, dimana variable eskogen sebagai variable lingkungan kerja dan motiva, dan endogen sebagai variable kinerja pegawai. Analisis jalur substruktur I dan substruktur II akan digambarkan model analisis jalur penelitian dengan menggunakan program SPSS.

Pengaruh variable human relations dan motivasi pada lingkungan kerja yang disajikan dalam Tabel 3 berikut:

\begin{tabular}{cccccc}
\multicolumn{5}{c}{ Tabel 3. Pengaruh Human Relations dan Lingkungan Kerja terhadap Motivasi Kerja } \\
\hline $\begin{array}{r}\text { Variabel } \\
\text { Endogen }\end{array}$ & Variabel Eksogen & $\begin{array}{c}\text { Koefisien } \\
\text { Jalur } \\
\text { (Beta) }\end{array}$ & $\begin{array}{c}\text { Nilai } \\
\text { Sig. }\end{array}$ & Keterangan & $\begin{array}{c}\text { Koefisien } \\
\text { Determinasi }\end{array}$ \\
\hline $\begin{array}{c}\text { Motivasi } \\
\text { kerja }\left(\mathrm{X}_{3}\right)\end{array}$ & Lingan relations $\left(\mathrm{X}_{1}\right)$ & 0,652 & 0,000 & Signifikan & $0,604=$ \\
\hline Sumber: Data Primer (Diolah, 2020) & 0,231 & 0,010 & Signifikan & $60,4 \%$ \\
\hline
\end{tabular}

Persamaan didapatkan pada sub struktur 1 yaitu : $\mathbf{X}_{\mathbf{3}}=\mathbf{0 , 6 5 2} \mathbf{X}_{\mathbf{1}}+\mathbf{0 , 2 3 1}$ $\mathbf{X}_{2}+\mathbf{e}_{1}$

Keterangan persamaan substruktur 1:

$\mathrm{b}_{1}=0,652$, artinya adanya pengaruh positif antara variabel human relations $\left(\mathrm{X}_{1}\right)$ terhadap motivasi kerja $\left(\mathrm{X}_{3}\right)$. Hal ini menunjukkan bahwa semakin baik human relations, maka motivasi kerja akan semakin tinggi. Begitu sebaliknya, semakin tidak baik human relations, maka motivasi kerja akan semakin rendah.

$\mathrm{b}_{2}=0,231$, menunjukkan bahwasanya terdapat pengaruh yang positif yakni lingkungan kerja $\left(\mathrm{X}_{2}\right)$ terhadap motivasi kerja $\left(\mathrm{X}_{3}\right)$.

Adapun pada hasil uji secara parsial pada variable, didapatkan bahwasanya penyebabnya yakni adanya pengaruh Human relations terhadap motivasi kerja dengan skor 0,652 dan signifikan pada level $0,000<0,05$ hal ini menunjukkan terdapat pengaruh kerja pada pegawai kementrian agama di Sumatra Barat. Pada lingkungan kerja terhadap motivasi kerja terdapat pengaruh yang signifikant terhadap motivasi kerja, dengan level signifikan $0,010<0,05$

Dengan demikian dapat diperoleh diagram jalur untuk SubStruktur 1 yang dapat digambarkan sebagai berikut:

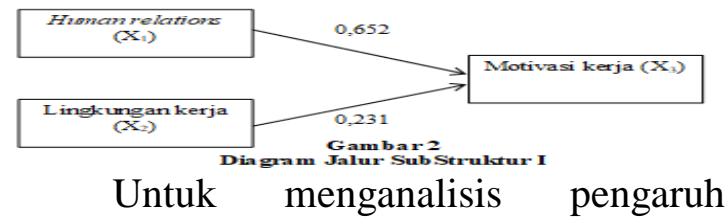
variabel human relations, lingkungan kerja dan motivasi kerja terhadap kinerja pegawai yang disajikan dalam Tabel 4 berikut:

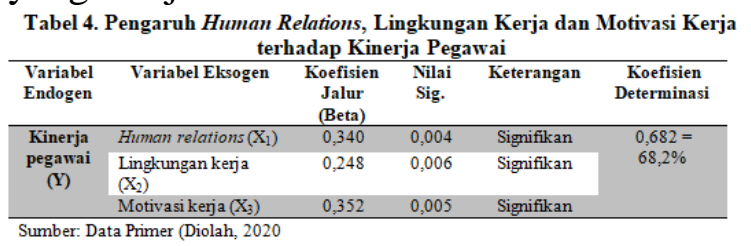

Adapun persamaan pada table 4 dapat diketahui bahwasanya persamaan pada substruktur didapatkan hasil yakni : $Y=0,340 X_{1}+0,248 X_{2}+0,352 X_{3}+e_{2}$ Keterangan persamaan substruktur 2 :

$\mathrm{b}_{1}=0,340$, menunjukkan bahwasanya pengaruh positif antara variabel human relations $\left(\mathrm{X}_{1}\right)$ terhadap kinerja pegawai $(\mathrm{Y})$. Hal ini menunjukkan bahwa semakin baik human relations, maka kinerja pegawai 
akan semakin meningkat. Begitu sebaliknya, semakin tidak baik human relations maka kinerja pegawai akan semakin menurun. $b_{2}=0,248$, bahwasanya terdapat pengaruh positif antara variabel lingkungan kerja $\left(\mathrm{X}_{2}\right)$ terhadap kinerja pegawai (Y). Hal ini menunjukkan bahwa semakin baik lingkungan kerja, maka kinerja pegawai akan semakin meningkat. Begitu sebaliknya, semakin tidak baik human relations, maka kinerja pegawai akan semakin menurun.

$b_{3}=0,352$, adanya pengaruh antara variable motivasi kerja $\left(\mathrm{X}_{3}\right)$ dan variable kinerja pegawai $(\mathrm{Y})$

Dari hasil uji parsial yang didapatkan pada masing masing variable, didaapatkan hasil yakni dimana pengaruh Human Relations terhadap Kinerja Pegawai kinerja pegawai diperoleh nilai $\operatorname{pyx}_{1 \cdot \mathrm{x} 1}=0,340$ dengan tingkat level signifikan $0,004<0,05$. terdapat pengaruh yang signifikan. Lingkungan Kerja terhadap Kinerja Pegawai diperoleh nilai $\operatorname{pyx}_{2 \cdot \mathrm{X} 2}=0,248$ dengan tingkat level signifikan $0,006<0,05$. Motivasi Kerja terhadap Kinerja Pegawai juga memiliki pengaruh, diperoleh nilai $\operatorname{\rho yx}_{3 \cdot x_{3}}=0,352$ dengan tingkat level signifikan $0,005<$ 0,05 .

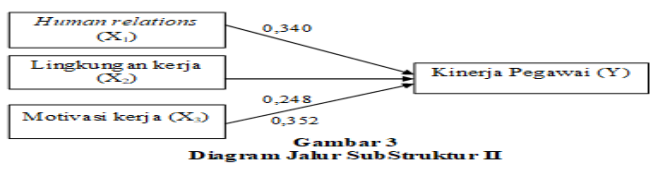

Koefisien determinasi juga diperoleh data, yang menunjukkan bahwasanya :

\begin{tabular}{clc}
\multicolumn{3}{c}{ Tabel 5. Hasil Perhitungan Koefisien Determinasi } \\
\hline Persamaan & \multicolumn{1}{c}{ Hubungan Variabel } & R Square \\
Substruktur 1 & $\begin{array}{l}\text { Human relations dan lingkungan kerja terhadap motivasi } \\
\text { kerja }\end{array}$ & 0,604 \\
Substruktur 2 & $\begin{array}{l}\text { Human relations, lingkungan kerja dan motivasi kerja } \\
\text { terhadap kinerja pegawai }\end{array}$ & 0,638 \\
\hline Sumber: Data Primer (Diolah, 2020) \\
Variable yang menghubungkan
\end{tabular}
antara variable eksogen dan endogen (Intervening) didapatkan hasil bahwasanya dengan dengan uji analisis jalur (path analysis), didapatkan hasil : bahwasanya motivasi kerja dengan variable intervening memiliki pengariuh terhadap human relations dengan kinerja pegawai. Untuk menentukan pengaruh dari suatu variabel eksogen ke variabel endogen baik secara langsung maupun tidak langsung dapat dilihat sebagai berikut :

Pengaruh langsung variabel $\mathrm{X}_{1}$ terhadap $\mathrm{Y}$ $\mathrm{Y} \leftarrow \mathrm{X}_{1} \rightarrow \mathrm{Y}\left(\rho \mathrm{yx}_{1}\right)\left(\rho \mathrm{yx}_{1}\right)=(0,340) \mathrm{x}$ $(0,340)=0,116=11,6 \%$ Pengaruh tidak langsung dari $\mathrm{X}_{1}$ ke $\mathrm{Y}$ melalui $\mathrm{X}_{3}$

$\mathrm{Y} \leftarrow \mathrm{X}_{1} \Omega \mathrm{X}_{3} \rightarrow \mathrm{Y}\left(\rho \mathrm{yx}_{1}\right)\left(\rho \mathrm{x}_{3} \cdot \mathrm{x}_{1}\right)\left(\rho \mathrm{yx}_{3}\right)=$ $(0,340) \times(0,652) \times(0,352)=0,078=7,8 \%$

Pengaruh langsung variabel $\mathrm{X}_{2}$ terhadap $\mathrm{Y}$ $\mathrm{Y} \leftarrow \mathrm{X}_{2} \rightarrow \mathrm{Y}\left(\rho \mathrm{yx}_{2}\right)\left(\rho \mathrm{yx}_{2}\right)=(0,248) \mathrm{x}$ $(0,248)=0,061=6,1 \%$

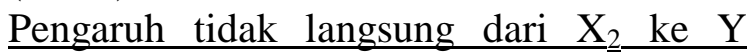
${\underline{\text { melalui } \mathrm{X}_{3}}}$

$\mathrm{Y} \leftarrow \mathrm{X}_{2} \Omega \mathrm{X}_{3} \rightarrow \mathrm{Y}\left(\rho \mathrm{yx}_{2}\right)\left(\rho \mathrm{x}_{3} \cdot \mathrm{x}_{2}\right)\left(\rho \mathrm{yx}_{3}\right)=$ $(0,248) \times(0,231) \times(0,352)=0,020=2,0 \%$

Dari data informasi dan olahan data didapatkan pengaruh langsung terhadap lingkungan kerja $(0,061)$ atau $6,1 \%$, pengaruh tidak langsung $(0,020)$ atau $2 \%$. Dari path analysis dapat ditarik kesimpulan bahwa lingkungan kerja berpengarih terhadap motivasi kerja. Diperoleh model analisis jalur yang dapat digambarkan sebagai berikut:

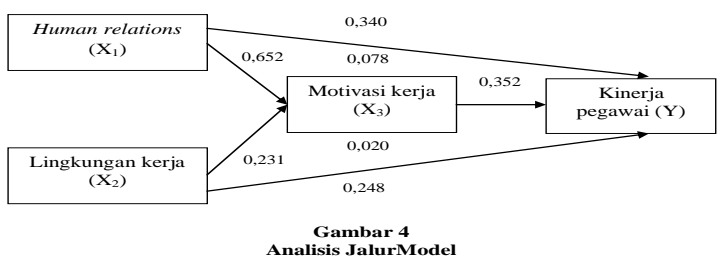

Adapun hasil dari ringkasan hasil uji hipotesis melalui analisis jalur didapatkan informasi sebagaimana pada tabel berikut :

\begin{tabular}{lllc}
\hline Hipotesis & Pernyataan & Hasi Uji \\
$\mathrm{H}_{1}$ & $\begin{array}{l}\text { Human relationsberpengaruh terhadap } \\
\text { motivasi kerja pegawai Kantor Wilayah } \\
\text { Kementerian Agama Provinsi Sumatera Barat. }\end{array}$ & Diterima \\
$\mathrm{H}_{2}$ & $\begin{array}{l}\text { Lingkungan kerja berpengaruh terhadap } \\
\text { motivasi kerja pegawai Kantor Wilayah } \\
\text { Kementerian Agama Provinsi Sumatera Barat. }\end{array}$ & Diterima \\
& $\begin{array}{l}\text { Human relationsberpengaruh terhadap kinerja } \\
\text { pegawai Kantor Wilayah Kementerian Agama }\end{array}$ & Diterima \\
$\mathrm{H}_{3}$ & $\begin{array}{l}\text { Provinsi Sumatera Barat. } \\
\text { kingkungan kerja berpengaruh terhadap } \\
\mathrm{H}_{4}\end{array}$ & Dinerja pegawai Kantor Wilayah Kementerian \\
& $\begin{array}{l}\text { Agama Provinsi Sumatera Barat. } \\
\mathrm{H}_{5}\end{array}$ & $\begin{array}{l}\text { Motivasi kerja berpengaruh terhadap kinerja } \\
\text { pegawai Kantor Wilayah Kementerian Agama }\end{array}$ & Diterima \\
Provinsi Sumatera Barat. & \\
\hline
\end{tabular}




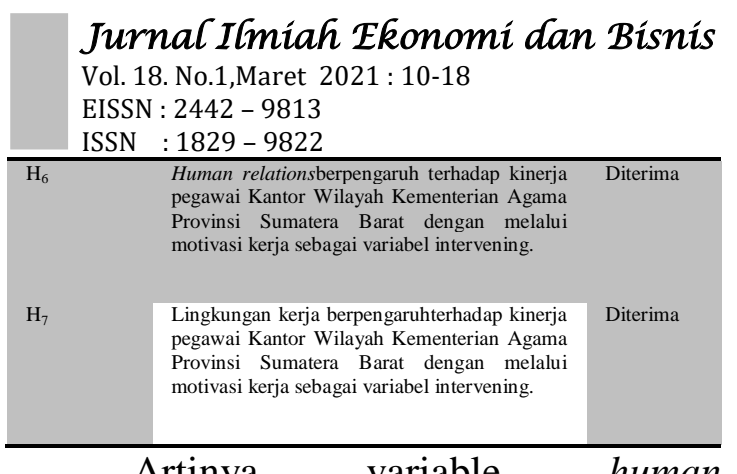

relationship memiliki pengaruh terhadap motivasi kerja. Adapun besaran pengaruh human relationship $(0,652)$ dan nilai signifikant $(0,000)$ artinya lebih kecil dari $\alpha: 0,05$. Dwiyanti (2015) membuktikan bahwa human relations berpengaruh terhadap motivasi kerja. Lengkey, dkk (2015) human relationship berpegaruh terhadap motivasi kerja.

Hasil uji hipotesi yang kedua juga menujukkan bahwa human relationship adanya pengaruh positif terhadap kinerja pegawai. Adapun besarnya koefisien pada veriable jalur yakni $(0,231)$ dengan tingkat signifikant $(0,010)$ artinya nilai $\alpha: 0,05$ lebih kecil tingkat signifikannya. Hal ini juga membuktikan bahwa lingkungan kerja yang semakin baik akan memberikan pengaruh terhadap motivasi kerja begitupun sebaliknya. Penelitian ini sejalan dengan kajian yang dilakukan oleh Haribowo dan Nurkhayati, 2019. Temuan ini juga didukung penelitian Prakoso,dkk, 2014.

Hasil uji hiptesis ketiga, didapatkan bahwa koefisien terhadap human relationship yakni $(0,340)$ dan nilai signifikant $(0,004)$ artinya nilai signifikan lebih kecil $\alpha: 0,05$. Hal ini menunjukkan bahwa nilai human relationship yang semakin baik akan memberikan dampak positif terhadap kinerja pegawai begitu juga sebaliknya.

Dari hasil pengujian hipotesis ketiga ditemukan bahwa variabel human relations berpengaruh positif dan signifikan terhadap kinerja pegawai Kantor Wilayah Kementerian Agama Provinsi Sumatera Barat. Besaran koefisien jalur variabel human relations adalah 0,340 dan signifikan sebesar 0,004. Nilai signifikan tersebut lebih kecil dari $\alpha$
$=0,05$. Hal ini dapat diartikan bahwa variabel human relations berpengaruh positif dan signifikan terhadap kinerja pegawai. Dengan demikian, hipotesis ketiga $\left(\mathrm{H}_{3}\right)$ dalam penelitian dinyatakan dapat diterima. Hal ini bermakna bahwa jika semakin baik human relations, maka kinerja pegawai akan semakin tinggi. Begitu sebaliknya, semakin tidak baik human relations maka kinerja pegawai akan semakin rendah dengan asumsi variabel lain selain human relations dianggap konstan.

Analisis secara deskriptif, persepsi pegawai terhadap human relations berada pada kategori cukup baik (70,9\%). Data ini menunjukkan bahwa human relations belum terlaksana dengan baik dan masih perlu ditingkatkan agar tercipta hubungan yang harmonis. Manuputty (2018) yang menyatakan bahwa human relations berpengaruh positif terhadap kinerja hal ini juga didukung oleh hasil penelitian Susanti, dkk (2014)

Hasil pengujian hipotesis keempat ditemukan bahwa variabel lingkungan kerja berpengaruh positif dan signifikan terhadap kinerja pegawai, tingkat koefisien jalur variabel lingkungan kerja adalah $(0,248)$ signifikan sebesar $(0,006)$. Nilai signifikan tersebut lebih kecil dari $\alpha: 0,05$. Hal ini bermakna bahwa jika semakin baik lingkungan kerja, maka kinerja pegawai akan semakin tinggi, begitu sebaliknya.

Hasil analisis deskriptif menunjukkan persepsi pegawai terhadap lingkungan kerja berada pada kategori cukup baik $(73,14 \%)$. Data ini menunjukkan bahwa lingkungan kerja perlu ditingkatkan. Lingkungan kerja terbukti belum mampu menciptakan kondisi kerja yang baik, nyaman dan menyenangkan. Ini dibuktikan dari indikator terendah yang dipersepsikan oleh pegawai dengan kategori cukup baik yaitu penerangan/cahaya.

Fiqi (2018) lingkungan kerja yang kondusif dapat diciptakan oleh organisasi, terjalin hubungan yang harmonis dengan rekan kerja, terciptanya komunikasi yang baik antara pimpinan dan pegawai serta 
tersedia fasilitas atau perlengkapan kerja untuk pegawai maka kinerja pegawai semakin meningkat. Sejalan dengan Jaya (2014) dalam penelitiannya membuktikan bahwa lingkungan kerja berpengaruh signifikan terhadap kinerja pegawai. Artinya agar terwujud peningkatan kinerja harus ditunjang dengan lingkungan kerja yang baik dan kondusif.

Uji hipotesis kelima ditemukan bahwa variabel motivasi kerja berpengaruh positif dan signifikan terhadap kinerja pegawai. Besaran koefisien jalur variabel motivasi kerja adalah 0,352 dan signifikan sebesar 0,005. Nilai signifikan tersebut lebih kecil dari $\alpha$ $=0,05$. Hal ini dapat diartikan bahwa variabel motivasi kerja berpengaruh positif dan signifikan terhadap kinerja pegawai. Dengan demikian, hipotesis kelima $\left(\mathrm{H}_{5}\right)$ dalam penelitian dinyatakan dapat diterima. Hal ini bermakna bahwa jika semakin tinggi motivasi kerja, maka kinerja pegawai akan semakin tinggi. Begitu sebaliknya, semakin rendah motivasi kerja maka kinerja pegawai akan semakin rendah dengan asumsi variabel lain selain motivasi kerja dianggap konstan.

Hasil analisis deskriptif yang termuat dalam indikator masuk dalam kriteria cukup baik $(77,1 \%)$. Data ini menunjukkan bahwa motivasi kerja perlu ditingkatkan. Motivasi kerja terbukti belum mampu meningkatkan semangat kerja dan memenuhi kebutuhan pegawai di dalam organisasi. Ini dibuktikan dari indikator terendah yang dipersepsikan oleh pegawai dengan kategori cukup baik yaitu kebutuhan fisiologis (physiological needs). Hal ini menunjukkan bahwa instansi belum mampu memenuhi kebutuhan makan siang dan minum yang memadai serta menyediakan tempat istirahat yang nyaman pada saat jam istirahat sehingga membuat pegawai kurang bersemangat dalam menyelesaikan pekerjaan dan berdampak pada rendahnya kinerja pegawai.
Zameer, dkk (2014) menemukan bahwa motivasi kerja berpengaruh signifikan terhadap kinerja pegawai. Tanpa motivasi kerja, pegawai tidak dapat berjalan mencapai tujuannya. Hasil penelitian ini menunjukkan bahwa motivasi berperan penting dalam kinerja pegawai. Hal ini sejalan dengan penelitian terdahulu yang dilakukan oleh Aluf, dkk (2017). Moorhead dan Griffin (2013) motivasi merupakan serangkaian kekuatan yang membuat seseorang berperilaku dengan cara tertentu. Pemberian motivasi menjadi hal yang sangat penting dalam setiap organisasi. Pegawai dengan motivasi yang tinggi akan mampu mendorong pegawai lain untuk bekerja lebih semangat dan berkontribusi positif pada tanggung jawab pekerjaannya. Dengan tidak adanya dorongan akan motivasi pegawai.

Hasil pengujian hipotesis keenam diketahui bahwa nilai pengaruh tidak langsung variabel human relations terhadap kinerja pegawai melalui motivasi kerja yaitu sebesar 0,078 lebih kecil dari pengaruh langsung variabel human relations terhadap kinerja pegawai yaitu sebesar 0,116. Dari perhitungan path analysis tersebut, dapat disimpulkan bahwa human relations berpengaruh terhadap kinerja pegawai melalui motivasi kerja dengan pengaruh tidak langsung yang lemah. Hal ini bermakna bahwa human relations yang baik antar pegawai dengan rekan kerja, pegawai dengan atasan akan memberikan motivasi kepada pegawai untuk bekerja terlebih dahulu, yang selanjutnya berdampak pada hasil kinerjanya, akan tetapi pengaruhnya tidak signifikan.

Amrullah (2019) didapatkan bahwasanya human relationship akan akan dapat meningkatkan kinerja pegawai. Kebutuhan mereka pada dasarnya meliputi kebutuhan ekonomi, psikologis dan sosial. Susanti, dkk (2014) membuktikan bahwa human relations berpengaruh terhadap kinerja pegawai sejalan dengan pendapat Davis dalam Susanti, dkk (2014). 
Jurnal Ilmiah Ekonomi dan Bisnis

Vol. 18. No.1,Maret 2021 : 10-18

EISSN : $2442-9813$

ISSN : $1829-9822$

Berdasarkan pengujian hipotesis ketujuh diketahui bahwa nilai pengaruh tidak langsung variabel lingkungan kerja terhadap kinerja pegawai melalui motivasi kerja yaitu sebesar 0,020 lebih kecil dari pengaruh langsung variabel lingkungan kerja terhadap kinerja pegawai yaitu sebesar 0,020. Dari perhitungan path analysis tersebut, dapat disimpulkan bahwa terdapat pengaruh signifikan lingkungan kerja terhadap kinerja pegawai melalui motivasi kerja dengan pengaruh tidak langsung yang lemah. Hal ini bermakna bahwa lingkungan kerja yang baik dan kondusif dapat mempengaruhi motivasi kerja pegawai dan berdampak terhadap kinerja pegawai, akan tetapi pengaruhnya tidak signifikan.

Prakoso, dkk (2014) lingkungan kerja berpengaruh terhadap kinerja karyawan melalui motivasi kerja. Hasil ini sejalan dengan penelitian Jaya (2014) bahwasanya lingkungan kerja yang efektif dan kondusif akan memberikan dampak terhadap motivasi kerja pegawai.

\section{KESIMPULAN DAN SARAN}

Hasil kajian pada penelitian didapatkan kesimpulan yang menyatakan bahwasanya human relations dan lingkungan kerja terhadap kinerja pegawai (1)Human Relationship memiliki pengaruh terhadap motivasi kerja, kinerja pegawai, namun pada hasil juga menunjukan tidak memilki pengaruh pada kinerja pegawai (2)Lingkungan kerja juga berpegaruh terhadap motivasi, dan tidak memiliki pengaruh terhadap kinerja pegawai dan Motivasi kerja berpengaruh signifikan terhadap kinerja pegawai.

Adapun saran sebagai berikut:

(1)Human relations dalam kategori cukup baik dengan indikator terendah adalah hubungan perilaku dengan rekan kerja. Oleh karena itu, sebaiknya Instansi memberikan sosialisasi kepada semua pegawai agar pegawai dapat bersikap ramah dengan rekan kerja, menjaga komunikasi, saling membantu dan menghargai sehingga terjalin hubungan yang harmonis dalam bekerja demi tercapainya tujuan organisasi. (2)Hasil menunjukkan lingkungan kerja dalam kategori cukup baik dengan indikator terendah adalah penerangan/cahaya di tempat kerja. Untuk itu, Kantor Wilayah Kementerian Agama Provinsi Sumatera Barat perlu menambah penerangan/cahaya ditempat kerja dan memperbaiki lampu yang tidak berfungsi dengan baik agar penerangan dapat membantu pegawai melihat obyek-obyek yang dikerjakan lebih jelas sehingga menciptakan lingkungan kerja yang nyaman dan menyenangkan. (3)Motivasi kerja dalam kategori cukup baik dengan indikator terendah adalah kebutuhan fisiologis (physiological needs). Oleh karena itu, pihak Instansi harus menyediakan program makan siang dan minuman yang lebih baik serta menyediakan ruangan istirahat bagi pegawai yang representatif dan nyaman pada waktu istirahat agar motivasi kerja pegawai lebih meningkat dalam melakukan segala pekerjaan. (4) Berdasarkan hasil pengujian koefisien path analysis yang paling besar mempengaruhi kinerja pegawai adalah motivasi kerja, sehingga penulis menyarankan kepada Kantor Wilayah Kementerian Agama Provinsi Sumatera Barat untuk lebih memperhatikan indikatorindikator dalam meningkatkan motivasi kerja pegawai.

\section{DAFTAR PUSTAKA}

Adawiyah, Sa'diyah, E. (2019). Human Relations. Yogyakarta: Deepublish.

Afandi, P. (2016). Concept \& Indicator: Human Resources Management For Management Research. Yogyakarta: Deepublish.

Aluf, Al, Wilda., Sudarsih, Musmedi, Pudjo, D., Supriyadi. (2017). Assessing The Impact Of Motivation, Job Satisfaction, And Work Environment On The Employee Performance In Healthcare Services. International 
Journal of Scientific \& Technology Research, 6(10).

Arikunto, S. (2013). Prosedur Penelitian: Suatu Pendekatan Praktik. Jakarta: Rineka Cipta.

Asrifah. (2015). Pengaruh Human Relations Terhadap Kinerja Pegawai di Kantor Wilayah Kementerian Agama Provinsi Sulawesi Tengah. JurnalKatalogis, 3(2).

Azar, M., dan Shafighi, A. (2013). The Effect of Work Motivation on Employees' Job Performance: InternationalJournal of Academic Research in Business and Social Sciences, 3(9).

Bahri, Saiful, M. (2018). Pengaruh Kepemimpinan, Lingungan Kerja, Budaya Organisasi dan Motivasi Terhadap Kepuasan Kerja Yang Berimplikasi terhadap Kinerja Dosen. Surabaya: CV. Jakad Publishing.

Basori, Miftahul, A, N., Prahiawan, dan Wawan, Daenulhay. (2017). Pengaruh Kompetensi Karyawan dan Lingkungan Kerja Terhadap Kinerja Karyawan Melalui Motivasi Kerja Sebagai Variabel Intervening (Studi Pada PT. Krakatau Bandar Samudera). Jurnal Riset Bisnis dan Manajemen Tirtayasa, 1(2).

Darmadi, H. (2013). Metode Penelitian Pendidikan dan Sosial. Bandung: Alfabeta.

Duha, Timotius. (2014). Perilaku Oganisasi. Yogyakarta: Deepublish.

Dwiyanti, Rizki. (2015). Pengaruh Kompensasi, Lingkungan Kerja dan Human Relations terhadap Motivasi Kerja yang relevan Terhadap Produktivitas Kerja (Studi pada PT. Morich Indo Fashion Semarang). Jurnal Of Management, 1(1).

Fattah, H. (2017). Kepuasan Kerja dan Kinerja Pegawai, Budaya Organisasi, Perilaku Pemimpinan dan Efikasi Diri. Yogyakarta: Elmatera.
Ferzadiana, Novida, P. H., Soegiarto, Eddy, K., Ruliana, Titin. (2016). Pengaruh Disiplin Kerja dan Lingkungan Kerja Terhadap Kinerja Pegawai Pada Kantor Badan Kepegawaian Daerah Kabupaten Kutai Barat. Jurnal Ekonomia, 6(1).

Fiqi, Amir, M. (2018). Pengaruh Lingkungan Kerja dan Disiplin KerjaTerhadap Kinerja KaryawanPada CV. Tiara Abadi Pamekasan. Jurnal Ekomadania, 1(2). Ghozali, I. (2016.) Aplikasi Analisis Multivariate dengan Program IBM SPSS. 23. Semarang: BPFE Universitas Diponegoro.

Haribowo, Heni I, P., dan Nurkhayati, Isnaini. (2019). Pengaruh Lingkungan Kerja terhadap Motivasi Kerja Karyawan pada PT. Pupuk Sriwidjaja Palembang, Pusri Pemasaran Daerah (PPD) Jawa Tengah. Admisi dan Bisnis, 20(1).

Hartatik, Indah, Puji. (2014). Buku Praktis Mengembangkan SDM. Yogyakarta: Laksana.

Hasibuan, Malayu. S.P. (2014). Manajemen Sumber Daya Manusia (Edisi Revisi). Jakarta: BumiAksara.

Hasim, Djamil. (2019). Pengaruh Kepemimpinan, Motivasi Kerja dan Iklim kerja terhadap Kinerja Pegawai pada Dinas Kesejahteraan Sosial Kabupaten Biak Numfor. Surabaya: CV. Penerbit Qiara Media.

Jaya, Ichwanul. (2014). Pengaruh Disiplin Pegawai dan Lingkungan Kerja Terhadap Kinerja Aparatur Kelurahan Di Kecamatan Tanjung Redeb Kabupaten Berau. Jurnal Administrasi Publik dan Birokrasi, 1(3).

Kristanti, D., dan Pangastuti, R.L. (2019). Kiat-Kiat Merangsang Kinerja Karyawan Bagian Produksi. Surabaya: Media Sahabat Cendikia. Kustini, Henny. (2017). Communication Skill. Yogyakarta: Deepublish. 
Jurnal Ilmiah Ekonomí dan Bísnis

Vol. 18. No.1,Maret $2021: 10-18$

EISSN : $2442-9813$

ISSN : $1829-9822$

Lengkey, Lidia., Himpong, Meity, D., dan Norma N. Mewengkang. (2015). Peranan Human Relations Terhadap Motivasi Kerja Pegawai di Badan Kepegawaian Daerah (BKD) Propinsi Sulawesi Utara. E-journal Acta Diurna, 4(3).

Lestari, S. D., Syabarudin, D. A., Zurnali, C., \& Murad, D. F. (2018). The Influence of Work Environment, Competence and Compensation on Employee Performance through Intervening Variable Job Satisfaction at Bank BJB Tangerang Branch. International Journal of Academic Research in Business and Social Sciences, 8(11), 1572-1580.

Mahardika,Putu, A.C., Bagia, Wayan, I., dan Yulianthini, Nyoman, N. (2016). Pengaruh Kompensasi Dan Disiplin Kerja TerhadapKinerja Karyawan Pada Hotel Puri Bagus Lovina. e-Journal Bisma Universitas Pendidikan GaneshaJurusan Manajemen, 4(1).

Mangkunegara, Anwar P. (2014). Evaluasi Kinerja Sumber Daya Manusia. Bandung: Penerbit Refika Aditama.

Manuputty, Valentin. (2018). Analisis Pengaruh Tunjangan Kinerja Daerah (TKD), Human Relation dan Budaya Organisasi Terhadap Kinerja Aparatur Sipil Negara Dinas Tenaga Kerja dan Transmigrasi Provinsi Maluku. Jurnal SOSOQ, 6(2).

Noorbaya, S., Johan, Herni., dan Rahayu Sri. (2018). Komunikasi Kesehatan. Yogyakarta: Gosyen.

Prakoso, Rayka, D., Astuti, Endang, S., dan Ruhana, Ika. (2014). Pengaruh Lingkungan Kerja Terhadap Motivasi Kerja dan Kinerja Karyawan (Studi Pada Karyawan PT. AXA Financial Indonesia Cabang Malang). Jurnal Administrasi Bisnis (JAB), 14(2).
Priansa, Donni, J. (2014). Perencanaan dan Pengembangan Sumber Daya. Manusia. Bandung: Alfabeta.

Priyatno, D. (2014). SPSS 22 Pengolah Data Terpraktis. Yogyakarta: Andi.

Rahsel, Yoeyong. (2016). Pengaruh Motivasi Kerja terhadap Kinerja PegawaiAdministrasi Pusat Universitas Padjadjaran Bandung(Studi Pada Bagian Administrasi Umum UNPAD). Jurnal Manajemen Magister, 2(2).

Riduwan. 2012. Dasar-Dasar Statistika. Bandung:Alfabeta.

Rismawati dan Mattalata. (2018). Evaluasi Kinerja : Penilaian Kinerja Atas Dasar Prestasi Kerja Berorientasi Kedepan. Makasar: Celebes Media Perkasa.

Rivai, V., dan Sagala, Ella, J. (2013). Manajemen Sumber Daya Manusia untuk Perusahaan : Dari Teori ke Praktik. Edisi 2. Jakarta: PT. Rajagrafindo Persada.

Rosalina, Dhian., dan Apiska, Devi. (2018).

Dampak Kualitas Hubungan Antar Manusia (Human relation) Terhadap Kinerja Sumber Daya Manusia Organisasi, Jurnal Niagawan, 7(2).

Sangki, R. (2014). Lingkungan Kerja, Budaya Kerja dan Semangat Kerja Terhadap Kinerja Karyawan Ousourcing Pada Grapari Telkomsel Manado. Jurnal Emba, 2(3).

Santoso, Singgih. (2016). Panduan Lengkap SPSS Versi 23. Jakarta: ElekmediaComputindo.

Sedarmayanti. (2012). Manajemen Sumber Daya Manusia, Reformasi Birokrasi Manajemen Pegawai Negeri Sipil. Bandung: Rafika Aditama.

Sekaran, U., \& Bougie, R. (2016). Research Methods For Business: A SkillBuilding Approach (7th ed.). Haddington: John Wiley \& Sons.

Sofyan, D.K. (2013). Pengaruh Lingkungan Kerja Terhadap Kinerja Kerja Pegawai Bappeda. Malikussaleh Industrial Journal, 2(1). 